\title{
Introduction : Géographes de l'Est, 1840-1940
}

\section{André Weisrock}

\section{(2) OpenEdition}

\section{Journals}

Édition électronique

URL : http://journals.openedition.org/rge/4479

DOI : $10.4000 /$ rge.4479

ISSN : 2108-6478

\section{Éditeur}

Association des géographes de l'Est

\section{Édition imprimée}

Date de publication : 1 janvier 1999

ISSN : 0035-3213

\section{Référence électronique}

André Weisrock, «Introduction: Géographes de l'Est, 1840-1940 », Revue Géographique de l'Est [En ligne], vol. 39 / 1 | 1999, mis en ligne le 06 septembre 2013, consulté le 25 septembre 2020. URL http://journals.openedition.org/rge/4479; DOI : https://doi.org/10.4000/rge.4479

Ce document a été généré automatiquement le 25 septembre 2020

Tous droits réservés 


\title{
Introduction : Géographes de l'Est, 1840-1940
}

\author{
André Weisrock
}

1 Ce numéro de la Revue Géographique de l'Est ne prétend pas donner une image exhaustive de l'histoire de la géographie dans l'Est de la France entre 1840 et 1940. Il ne présente, au travers de cinq articles, pour l'essentiel consacrés à l'œuvre de personnages peu connus de leurs pairs, et a fortiori du grand public, que quelques aspects nouvellement étudiés de cette question.

2 La seconde moitié du XIXe siècle est la période d'émergence de la science géographique en Europe et de son institutionnalisation au sein des enseignements supérieurs. À cet égard, l'Allemagne précède largement la France : Carl Ritter occupe une chaire à Berlin dès 1820, rejoint par Alexander Von Humboldt en 1827. Il faut attendre les lendemains de la défaite de 1870 pour voir les gouvernements de la IIIe République charger Émile Levasseur d'organiser un enseignement de la géographie en élaborant des programmes susceptibles de remédier aux lacunes des Français en la matière. Encore les premières chaires sont-elles occupées par des professeurs à l'origine historiens, comme ce fut le cas à Nancy pour Paul Vidal de la Blache, puis B. Auerbach. Il y a donc dans cette période, et cela reste encore sensible pour la première moitié du XXe siècle, une différence fondamentale d'état d'esprit au sujet de la géographie, discipline à part entière, solidement ancrée dans l'univers intellectuel, illustrée par de grands noms d'une part, discipline aux débuts hésitants ou contradictoires, à la remorque de l'histoire, d'autre part. C'est pourquoi le contraste est accusé entre le géographe de Nancy, Bertrand Auerbach, historien à ses débuts, qui doit pérenniser la chaire de géographie à Nancy et hésite entre plusieurs voies sans en privilégier véritablement une, si ce n'est pour finir la géographie régionale (M.-C. Robic), et les géographes allemands installés à Strasbourg durant l'annexion : Georg Gerland, puis Karl Sapper, qui ont développé successivement sans aucun état d'âme leur conception propre de la géographie : une géographie physique axée sur la sismologie pour le premier, une géomorphologie tropicale pour le second, avec ainsi une constante tirant la géographie vers les sciences naturelles (H. Vogt). 
3 L'indépendance est peut-être aussi alors davantage un trait allemand, où l'unité est tardive et l'originalité des États bien établie ; en France au contraire, le centralisme a entraîné une telle domination de Paris que les écoles provinciales apparaissent bien timides ; l'article sur Auerbach le prouve abondamment. Nancy pouvait pourtant s'enorgueillir d'une vie intellectuelle et artistique de tout premier ordre aux alentours de 1900, avec une "Société de Géographie de l'Est » particulièrement active, aux Bulletins foisonnants, dans lesquels les universitaires de l'époque, dont Auerbach, n'hésitaient pas à écrire (J.-C. Bonnefont). Mais il est bien difficile de réussir à la fois en province et à Paris : Henri Hogard en est, a contrario, l'illustration précoce. Ce géologue spinalien devient président de la Société géologique de France en 1847, alors qu'il disparaît de la Société d'émulation du département des Vosges l'année suivante. Il n'est pas à vrai dire un géographe, mais sa démarche est celle d'un géomorphologue avant la lettre, établissant en France les bases d'une théorie glaciaire inspirée d'Agassiz. Il est resté cependant trop isolé de son vivant, sans moyens institutionnels, pour exercer une influence marquante hors d'un cercle restreint d'initiés. L'importance de son apport n'est vraiment apparue qu'après 1897 et la critique célèbre de la théorie glaciaire par le général De Lamothe (A. Weisrock).

4 La période 1918-1940 reste celle de l'antagonisme franco-allemand. Si Auerbach, fervent défenseur du régionalisme en France, semble avoir tout fait pour éviter de professer un nationalisme agressif (M.-C. Robic), ce n'est pas le cas de Heinrich Schmitthenner. Bien que consacrée à la géomorphologie, son œuvre s'inscrit en réaction à la théorie de l'évolution du relief de côtes de Davis, surtout semble-t-il lorsque celle-ci a finalement été adoptée par les géographes français. Fin connaisseur des côtes de Meuse où il fut "géologue de guerre", Schmitthenner en donne une explication plus naturaliste, plus précise et originale, se basant notamment sur la permanence de l'activité tectonique (M. Deshaies).

On voit tout le parti qu'il faudrait tirer de la position unique de la Lorraine et de l'Alsace, à la croisée des influences parisiennes et allemandes, en matière d'histoire de la pensée et du développement des idées scientifiques. Ce numéro n'est à ce titre qu'un modeste essai dont le lecteur voudra bien pardonner le caractère disparate et inachevé. 